\title{
Öğrenme Amaçlı Yazma Etkinliklerinin Fen Bilgisi Öğretmen Adaylarının Akademik ve Laboratuvar Başarılarına Etkisinin İncelenmesi
}

\author{
DOI: $10.26466 /$ opus. 846031 \\ * \\ Emre Yıldız - Gülşen Koçak ${ }^{* *}$ \\ * Dr., Atatürk Üniversitesi, Eğitim Fakültesi, Erzurum/Türkiye \\ E-Posta: emre.yildiz@atauni.edu.tr \\ ORCID: $\underline{0000-0001-7048-7545}$ \\ ** Dr., Atatürk Üniversitesi, Eğitim Fakültesi, Erzurum/Türkiye \\ E-Posta: gulsen.demir@atauni.edu.tr \\ ORCID: $\underline{0000-0001-7048-7545}$
}

\begin{abstract}
Öz
Bu araştırmanın amacı farklı öğrenme amaçl yazma türlerinin hazırlanmasının ve değerlendirilmesinin fen bilimleri öğretmen adaylarının akademik ve laboratuvar başarıları üzerindeki etkisini belirlemek ve öğrenme amaçlı yazma puanlarını karşılaştırmaktır. Araştırmada öğrenme amaçlı yazma türleri olarak mektup yazma ve poster hazırlama kullanılmıştır. Araştırmada deneysel desenlerden öntest-sontest kontrol gruplu yarı deneysel desen kullanılmıştır. Araştırma bir devlet üniversitesinde birinci sinıfa devam eden 88 öğretmen adayı ile yürütülmüş̧ür. Veri toplama aracı olarak akademik başarı testi, laboratuvar başarı testi ve mektup ve poster değerlendirme rubrikleri kullanılmıştır. Elde edilen verilerin analizinde, parametrik testlere uygun olduğu belirlendiğinden, betimsel istatistik, tek yönlü ANOVA ve bağımsız örneklemler t-testi analizinden faydalanılmıştır. Uygulama sonunda öğretmen adaylarının akademik ve laboratuvar başarıları arasında mektup, poster ve değerlendirme uygulamalar lehinde anlamlı farklılı̆̆ı olduğu bulunmuştur. Öğretmen adaylarının mektup yazma ve poster hazırlama puanları arasında istatistiksel olarak anlamlı farklılı̆̆ın olmadığı tespit edilmiştir. Farklı yazma türleri, farklı muhataplara yönelik hazırlatılabilir ve bu aktivitelerin akademik ve laboratuvar başarıları üzerindeki etkileri incelenebilir.
\end{abstract}

Anahtar Kelimeler: Akran değerlendirme, mektup, öğrenme amaçl yazma, poster. 


\title{
Investigation of the Effect of Writing to Learn Activities on Academic and Laboratory Achievement of Preservice Science Teachers
}

\begin{abstract}
This research aimed to determine the effects of different writing to learn activities on academic and laboratory achievement of pre-service science teachers, and compare writing to learn scores. In the research, writing letters and preparing posters were used as writing to learn types. In the research, quasiexperimental design with pretest-posttest control group, one of the experimental designs, was used. The research was conducted with 88 pre-service teachers attending the first year of a state university. As a data collection tool, the academic achievement test, the laboratory achievement test, and letter and poster evaluation rubrics were used. In the analysis of the obtained data, descriptive statistics, one-way ANO$V A$, and independent samples $t$-test were used as it was determined that it was suitable for parametric tests. At the end of the application, it was found that there is a significant difference between the academic and laboratory achievements of pre-service teachers in favor of letter, poster and evaluation applications. It was determined that there is no statistically significant difference between the letter writing and poster preparation scores of the pre-service teachers. Different types of writing can be prepared for different interlocutors and the effects of these activities on academic and laboratory achievements can be examined.
\end{abstract}

Keywords: : Letter, peer review, poster, writing to learn. 


\section{Giriş}

İletişimde kullanılan en önemli araçlardan biri olan yazma, yüzyıllardır eğitimde kullanılan bir öğrenme stratejisidir (Emig, 1977). Yazma yaygın kullanılan bir çalışma faaliyeti olup, en çok tercih edilen öğretici etkinliklerden birisidir (Klein, 1999). Akyol (2001), yazmayı; düşünceleri ifade etmek için gerekli olan işaret ve sembolleri motorsal olarak üretebilmek olduğunu ifade etmektedir. Bilimin dil olmadan gelişemeyeceği, bilim dille ayrı düşerse bilimin var olamayacağı (Norris and Phillips, 2003) mantığından yola çıkarak dilin dört öğesinden biri olan yazma bilim için kilometre taşıdır.

Bilgilerin hafızada kalması, rapor hazırlama, planlama ve düzenleme yapma, eleştirel düşünebilme, kavramsal becerilerden kendini yansıtma ve iletişime yardım etme bakımından (Sinaga and Feranie, 2017) yazma önemli rol oynar. Yazma çeşitli bilişsel süreçlerin gelişmesine yardım eder (Gregg and Steinberg 2016). Tekrarlanan çalışmalarda, yazma gibi yaklaşımların öğrencilere ciddi avantajlar sağladığı görülmüştür (Dunlosky vd., 2013; Lamb, Hand and Yoon, 2017). Haley-James (1982) yazmanın öğrenmeyi nasıl etkilediğini şu şekilde açıklamıştır:

- Yazma düşünmeye odaklanmiştır.

- Yazma kontrol etmek için düşündürür.

- Yazma kompleks düşünmeye izin verir.

- Yazma zihinsel yapıyı söze çevirir.

- Yazma çoklu algiya sahiptir.

- Yazma iletişimi motive eder.

Yazma konusunda; geleneksel yazma ve geleneksel olmayan yazma olarak iki farklı görüş bulunmaktadır (Prain, 2006). Geleneksel yazma stratejileri bilginin yeniden temsilinden ziyade bilginin kopyalanmasin destekleme eğilimindedir (Gunel, Hand and Prain, 2007). Burada ele alınan yazma; derste öğretmenler tarafından yapılan; anlatımlarla ilgili veya ders kitaplarında anlatılanlarla ilgili doğrudan notlar tutma, yapılan deneylerle ilgili laboratuvar raporları hazırlama gibi; öğrencinin pasif bir şekilde bilgiyi kaydettiği geleneksel yazma değil (Günel, Atila ve Büyükkasap, 2009), öğrenme amaçlı yazmadır (ÖAY). Buradan hareketle, geleneksel yazma okullarda uygulanan geleneksel laboratuvar raporu gibi format içerirken, ÖAY; posterler, mektuplar, broşürler, 
hikâyeler, günlükler gibi geleneksel olmayan yazma etkinliklerini içermektedir (McDermott and Hand, 2010; Yaman, 2018).

ÖAY, feni bir disiplin olarak anlamaya ve fen kavramlarını zengin anlatımlarla yapılandırmaya yardım eder (Jang and Hand, 2017). Zengin anlatımları, yazan kişinin kendi kelimeleriyle önemli bilgiler içinden seçip alarak yapması, yazan kişiye büyük fayda sağlar (Chi, 2009). ÖAY etkinlikleri; bilimsel içerikleri anlamaya, kritik düşünmeye, fikirleri ifade etmeye, işbirlikli öğrenmeye ve iletişim becerilerini geliştirmeye (Chatel, 1997; Klein, 1999; Mason and Boscolo, 2000), derse katılıma, daha iyi öğrenmeye, öğrenme ve öğretme sürecinde memnuniyeti artırmaya (Gunel, Hand and Mcdermott 2009; Hand, Yang, and Bruxwoort, 2007; Sinaga and Feranie, 2017) katkıda bulunur. Yine ÖAY aktiviteleri öğrencilerin; üst düzey zihinsel süreç becerilerini geliştirerek eleştirel düşünmeyi sağlaması, yeni bilgi dağarcığı oluşturması ve iletişim yeteneğinin artması bakımından ciddi katkılar sağlar (Hand vd., 2018; Klein, 1999; Yıldız and Büyükkasap, 2011). Böylece, ÖAY; bilgiyi yapılandırmayı sağlayarak (Brewster and Klump, 2004; Carter, 2007; Comer, Clark and Canelas, 2014; Sorcinelli and Elbow, 1997; Yore, Hand and Prain, 1999) epistemik bir araç olduğunu gösterir (Prain and Hand, 2016).

ÖAY etkinliklerinin; yazma aracı, muhatabı, amacı, tipi ve konusunu içeren model Hand ve Prain (2002) tarafından özet şablon şeklinde oluşturulmuştur. Bu şablon Şekil 1'de verilmiştir.

Brewster ve Klump (2004), ÖAY aktivitelerinin başarılı olması için bazı stratejiler sunmuşlardır. Bunlar: 1. İhtiyaç değerlendirmesi için başlama - 2. Ebeveynleri bu sürece dahil etme - 3. Öğretmen desteğini oluşturma - 4. Profesyonel gelişimleri destekleme - 5. Öğretmen liderliğini teşvik etme - 6. Yazma incelemeleri için ortak bir sistem kurma 7. Plan yapmak için yeterli zaman ayırma - 8. Yazma öğrenmeleri ve incelemeleri için zaman yaratma - 9. Program sonucunu değerlendirme.

Bu çalışma yukarıda bahsi geçen hususlara dikkat edilerek yürütülmüş; mektup ve poster çalışmaları farklı açılardan incelenerek alanyazına katkı sağlamaya çalışılmıştır. Mektup, bir ÖAY aktivitesi olarak, belirlenen konuyla ilgili olarak genellikle bir muhataba açiklamalarda bulunmak için kullanılmaktadır (Aktepe, 2020; Uzoğlu ve Gürbüz, 2013). Mektup, bir muhataba yönelik yazıldığından dolayı yazanın 
açıklayıcı olma çabası ön plandadır. Mektup yazmanın amacı; hakkında yazdığı konuyu, olayı ya da kavramı muhatabına en kolay anlaşılır bir şekilde açıklayabilmektir (Yıldız, 2014). Poster ise öğrencilerin çalışmalarını resim ve grafikle özetleyebildikleri öğrenme amaçlı yazma çeşididir. Posteri görsel bakımdan ilginç kılabilmek ve anahtar noktalara ilgiyi çekebilmek için grafikler, tablolar, resimler, örnekler ve diğer sanat eserleri kullanılır (Köklü, 2001). Mektup yazma ve poster hazırlama gibi ÖAY çeşitlerinin her birinin alanyazına ciddi katkıları vardır. Uluslararası çalışmalara bakıldığında ÖAY'ye geniş yer verilmesine karşın (Daşdemir, Cengiz ve Uzoğlu, 2015) halen daha ulusal alanyazında ÖAY istenilen noktaya ulaşamamıştır. Bu çalışmada, laboratuvar ortamında geleneksel rapor yazmak yerine, alternatif olarak farklı öğrenme amaçlı yazma çeşitlerinin birlikte incelenmesinin ilgili alana yönelik yapılacak araştırmalara katkı sağlaması beklenmektedir.

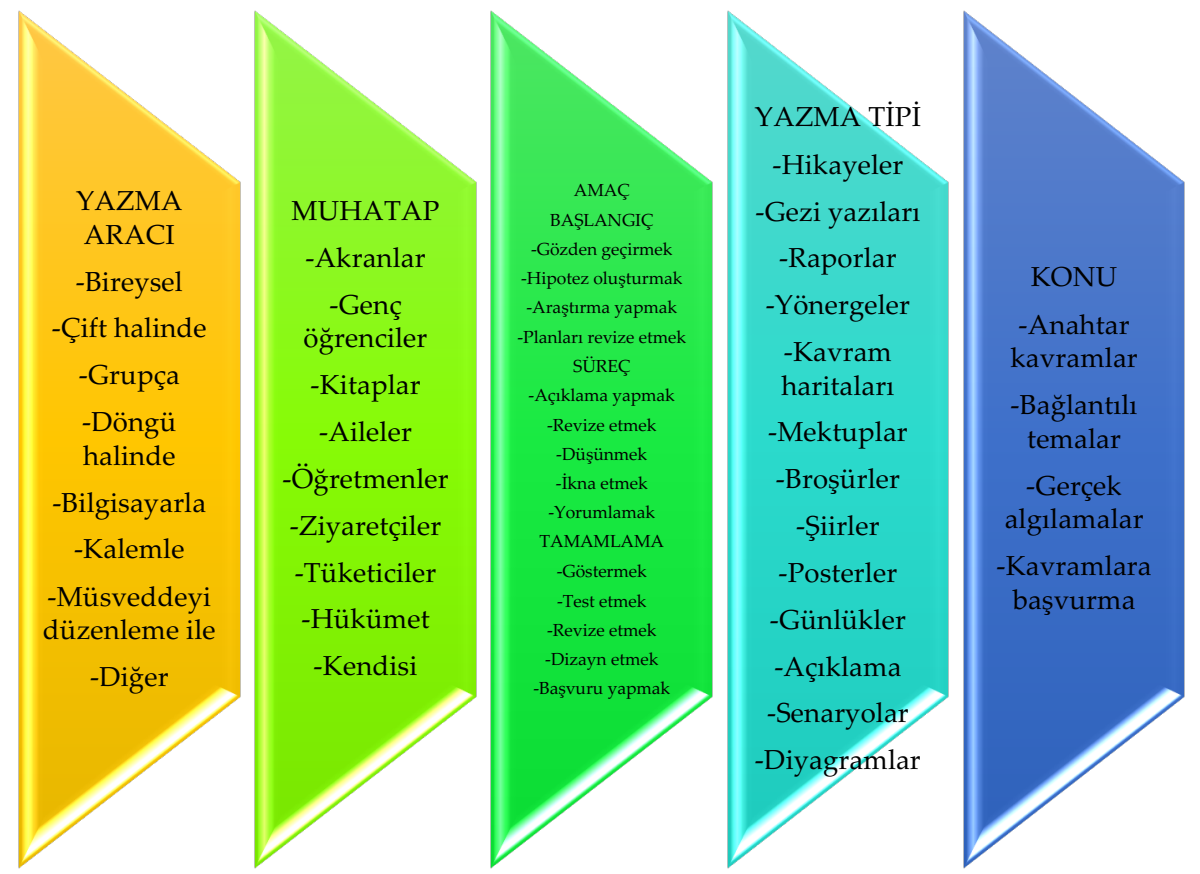

Şekil 1. Öğrenme Amaçlı Yazma Modeli (Hand and Prain, 2002) 
Bu araştırmanın amacı öğrenme amaçlı yazma türlerinden mektup ve poster çalışmalarının hazırlanmasının ve değerlendirilmesinin fen bilimleri öğretmen adaylarının akademik ve laboratuvar başarıları üzerindeki etkisini belirlemek ve mektup yazma ve poster hazırlama puanlarını karşılaştırmaktır. Bu bağlamda aşağıdaki araştırma soruları cevaplanmaya çalışılmıştır:

- Mektup yazan, poster hazırlayan, akranları tarafından hazırlanan bu öğrenme amaçlı yazma etkinliklerini değerlendiren ve klasik rapor hazırlayan öğretmen adaylarının Genel Fizik Laboratuvarı I dersi akademik başarıları arasında istatistiksel olarak anlamlı bir farklılık var midir?

- Mektup yazan, poster hazırlayan, akranları tarafından hazırlanan bu öğrenme amaçlı yazma etkinliklerini değerlendiren ve klasik rapor hazırlayan öğretmen adaylarının Genel Fizik Laboratuvarı I dersi laboratuvar başarıları arasında istatistiksel olarak anlamlı bir farklılık var midır?

- Öğretmen adaylarının öğrenme amaçlı yazma türlerinden mektup ve poster hazırlama puanları arasında istatistiksel olarak anlamlı farklılık var midır?

\section{Yöntem}

Araştırmada nicel araştırma modeli benimsenmiş ve deneysel desenlerden öntest-sontest karşılaştırma gruplu yarı deneysel desen kullanılmıştır (McMillan and Schumacher, 2010). Uygulamanın başlangıcında Akademik Başarı Testi (ABT-ön) ve Laboratuvar Başarı Testi (LBT-ön) öntest olarak uygulanmıştır. Uygulamaya üç deney grubu bir tane de kontrol grubu olmak üzere toplam dört grup alınmıştır. Deney Grubu-1'de laboratuvar raporları ÖAY etkinliklerinden mektup ile, Deney Grubu-2'de ise poster ile hazırlanmıştır. Deney Grubu-3 laboratuvar raporlarını klasik rapor yöntemi ile hazırlamış ve buna ek olarak Deney Grubu-1 ve 2'deki öğretmen adaylarının hazırladıkları mektup ve posterleri değerlendirmiştir. Kontrol grubu olarak seçilen grupta bulunan öğretmen adayları laboratuvar raporlarını klasik rapor yöntemi ile hazırlamışlardır ve bu grupta başka bir uygulama yapılmamıştır. Uygulamaların tamamlanmasının ardından Akademik Başarı 
Testi (ABT-son) ve Laboratuvar Başarı Testi (LBT-son) tüm deney gruplarına ve kontrol grubuna sontest olarak uygulanmıştır. Öğretmen adaylarının gerçekleştirdiği mektup ve poster çalışmalarının değerlendirilmesinde ise mektup ve poster değerlendirme rubrikleri kullanılmıştır. Araştırmanın deneysel planı Şekil 2'de verilmiştir.
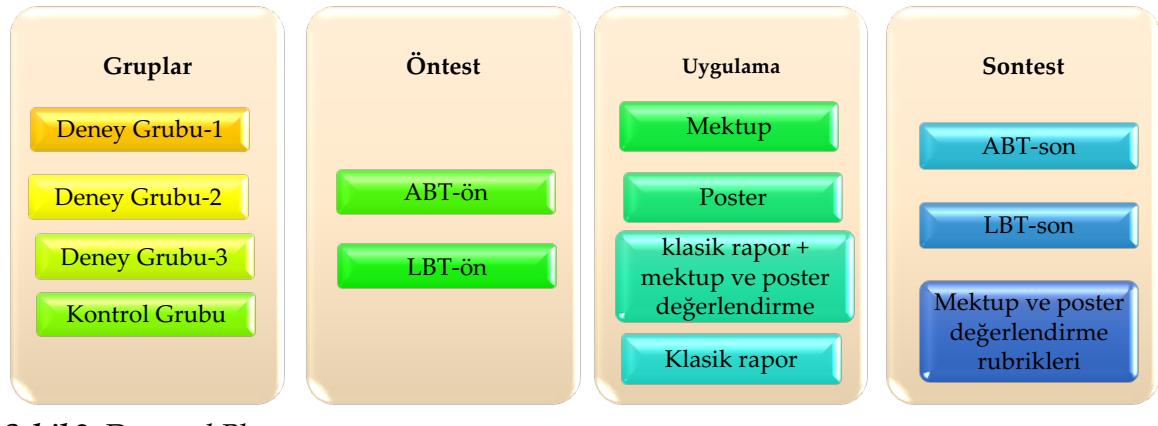

Şekil 2. Deneysel Plan

\section{Çalışma Grubu}

$\mathrm{Bu}$ araştırma, bir devlet üniversitesinde öğrenim gören 88 birinci sınıf fen bilimleri öğretmen adayı ile yapılmıştır. Öğretmen adaylarından $24^{\prime} \ddot{u}$ öğrenme amaçlı yazmada mektup hazırlayan Deney Grubu-1'e, 20'si öğrenme amaçlı yazmada poster hazırlayan Deney Grubu-2'ye, 24'ü klasik deney raporu hazırlamanın yanında hazırlanan mektup ve posterleri değerlendiren Deney Grubu-3'e ve 20'si yalnızca klasik deney raporu hazırlayan kontrol grubuna atanmıştır. Öğretmen adaylarının cinsiyete göre dağılımları Şekil 3'te verilmiştir.

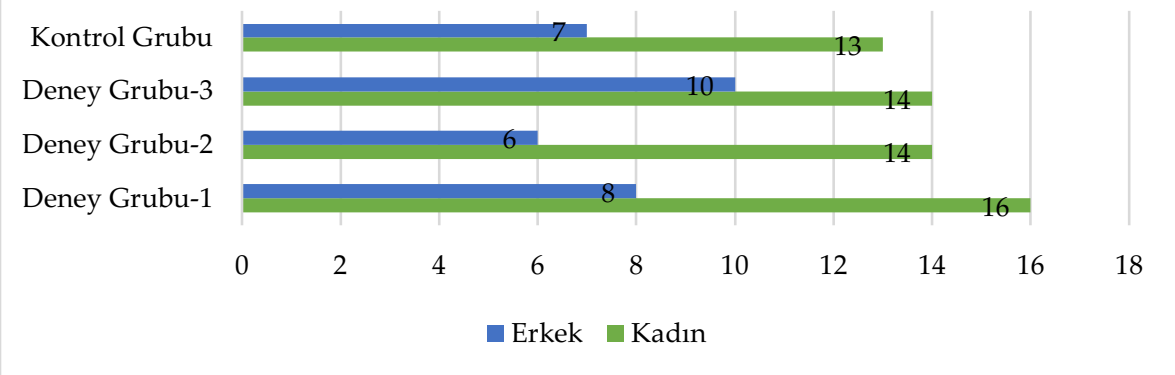

Şekil 3. Öğretmen Adaylarmmn Cinsiyete Göre Dă̆gllmları 


\section{Verilerin Toplanması}

01.12.2020 tarihli ve 56785782-050.02.04-E.2000301069 say1l Atatürk Üniversitesi Sosyal ve Beşeri Bilimler Etik Kurul Uygunluk-onay belgesine göre bu araştırmanın gerçekleştirilmesinde bilim etiğine aykırı bir durum yoktur.

\section{Veri toplama araçları}

Araştırmada veri toplama aracı olarak;

- Öğretmen adaylarının akademik başarılarını belirlemek amacıyla $\mathrm{ABT}$,

- Laboratuvar başarılarını tespit etmek amaciyla LBT ve

- Mektup ve poster çalışmalarını değerlendirmek amacıyla rubrikler kullanılmıştır.

Akademik başar testi:ABT, Genel Fizik I Laboratuvar dersinin konularını kapsayacak şekilde geçerliği ve güvenirliği sağlanmış; Uzun (2013)'un kullandığı 31 çoktan seçmeli sorudan oluşmaktadır. Test maddelerinin ortalama güçlük indeksi 0,50 olarak bulunmuştur. Madde ayırt edicilik indeksi düşük olan maddelerde düzenleme yapılmış ve ayırt edicilik indeksleri istenir düzeye çekilmiştir. Testin Cronbach Alpha güvenirlik katsayısı 0,72 olarak hesaplanmıştır. Bu araştırma için testin KR-20 güvenirlik katsayısı 0,74 olarak hesaplanmıştır. Test, doğru cevaplar 3,23 puan, boş bırakılanlar ve yanlış cevaplar 0 puan verilerek değerlendirilmiştir. Testten alınabilecek maksimum puan 100 ve minimum puan $0^{\prime}$ dır.

Laboratuvar başan testi:Araştırmada kullanılan laboratuvar başarı testi araştırmacılar tarafından hazırlanmıştır. Öncelikle uygulama sürecinde yapılacak deneylerin bir listesi hazırlanmıştır. Deneylerin tamamını kapsayacak şekilde 10 tane açık uçlu sorudan oluşan bir sınav ve ayrıntılı cevap anahtarı hazırlanmıştır. Sorular ve cevap anahtarları öncelikle daha önce Genel Fizik Laboratuvarı I dersini vermiş olan 2 Fen Bilgisi Eğitimi alan uzmanı tarafından incelenmiştir. Alan uzmanlarının görüşlerine göre testin yalnızca Genel Fizik Laboratuvarı I başarısını 
ölçmeye yönelik hazırlandığı, konu kapsamını tam olarak sağladığı ve iki sorunun düzeltilerek kullanılması gerektiği belirlenmiştir. Sorularda uzmanların istediği düzenlemeler yapılarak uygulanmaya hazır hale getirilmiştir. Test iki araştırmacı tarafından birbirinden bağımsız olarak cevap anahtarına bağlı kalınarak değerlendirilmiştir. İki araştırmacının değerlendirmeleri arasındaki Kappa katsayısı 0,69 olarak hesaplanmıştır. Testten alınabilecek maksimum puan 100 ve minimum puan 0 'dır.

Mektup ve poster değerlendirme rubrikleri:Mektup ve Poster Değerlendirme Rubrikleri öğretmen adaylarının hazırladıkları yazma çalışmalarının daha objektif bir biçimde değerlendirilmesi amacıyla araştırmacılar tarafından hazırlanmıştır. Rubrikler yazma çalışmasının içeriği, yazma türüne uygunluğu, yazım ve dil bilgisi, üslup ve tarzı, hitap edilen kesme uygunluğu, bilgi zenginliği ve öğreticiliği açısından değerlendirme kriterlerini içermektedir. Her iki rubrik de 5'li likert tipi 10 ölçüt içerecek şekilde hazırlanmıştır. Ölçüt tamamen sağlanıyorsa 5 puan ölçüt hiç sağlanmıyorsa 1 puan şeklinde 1-5 arasında puanlandırılmıştır. Grupların her bir yazma çalışmasından alabileceği maksimum puan 50 ve minimum puan $10^{\prime}$ dur. Toplam yazma puanları belirlenirken tüm yazma puanlarının ortalaması alınmış ve elde edilen puan 100'lük sisteme dönüştürülmüştür.

\section{Verilerin Analizi}

İstatistiksel analizler gerçekleştirilmeden önce parametrik testlerin uygulanması için önkoşul varsayımların sağlanıp sağlanmadığı test edilmiştir. Normallik dağılımları; ortalama ve ortanca değerleri, basıklık ve çarpıklık katsayıları ve Shapiro-Wilk normallik testi ile incelenmiştir. Normal dağılım varsayımlarının sağlandığı tespit edildiğinden uygulamadan elde edilen verilerin analizlerinde parametrik testlerden; betimsel istatistik, tek yölü varyans analizi ve bağımsız örneklemler t-testi kullanılmıştır. İstatistiksel analizlerde anlamlılık düzeyi 0.05 alınmıştır. Analizlerde SPSS 22 paket programı kullanılmıştır. 


\section{Uygulama}

Uygulama tüm kontrol ve deney gruplarında 13 hafta (haftalık ardışık 2 saatlik ders) boyunca Genel Fizik Laboratuvarı I dersi kapsaminda araştırmacılar tarafından yürütülmüştür. Ders kapsamında gerçekleştirilen deneyler Şekil 4'te verilmiştir.

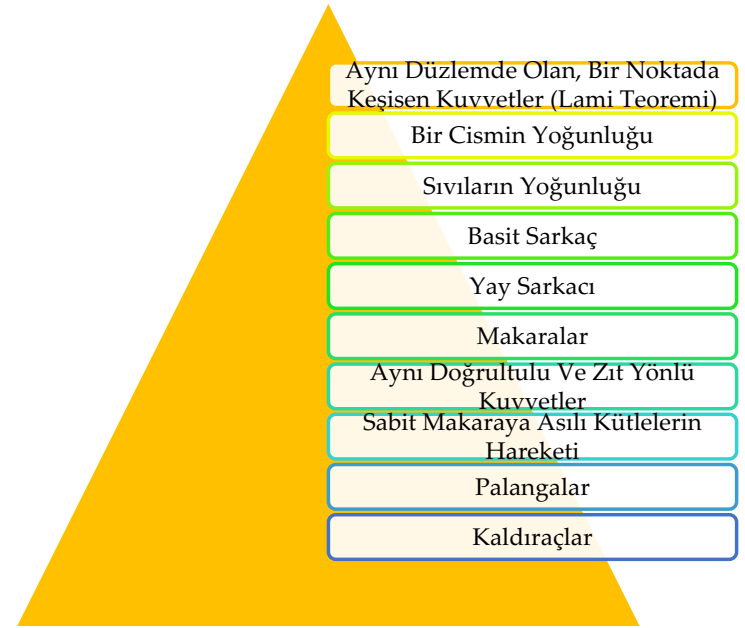

Şekil 4. Uygulama Kapsamında Yapılan Deneyler

Öğretmen adayları öncelikle Deney Grubu-1, Deney Grubu-2, Deney Grubu-3 ve kontrol grubu olmak üzere dört ana gruba ayrılmıştır. Her gruptaki öğretmen adayları ikişer veya üçer kişilik alt gruplara ayrılmıştır. Oluşturulan alt gruplar laboratuvarda birlikte çalışarak ders içeriğinde belirtilen deneyleri yapmışlardır. Öğretmen adayları deneyleri yaparken araştırmacılar gruplar arasında dolaşarak deney hakkında temel bilgiler vermiş, grupların sorularını cevaplamış ve takıldıkları noktalarda yardımcı olmuştur. Uygulama gruplarında dersin işleniş biçimi aynı olmakla birlikte yalınızca öğretmen adaylarının hazırladıkları rapor türleri farklılık göstermiştir.

Mektup: Deney Grubu-1 olarak seçilen grupta öğretmen adayları yaptıkları deneylerin raporlarını ÖAY türlerinden mektup olarak hazırlamış ve bir sonraki hafta yapılan laboratuvar dersinde araştır- 
macılara teslim etmiştir. Mektup yazımında aşağıda belirtilen kriterler dikkate alınmıştır:

- Laboratuvarda gruplar halinde çalışan öğretmen adayları mektupları bireysel olarak hazırlamıştır.

- Mektupları bir akranlarına göndermeye yönelik yazmaları istenmiştir.

- Mektupta içten, samimi bir dil kullanmaları istenmiştir. Kullanılan dilin akran seviyesine uygun olması gerektiği vurgulanmıştır.

- Mektup formatına uygun şekilde deney hakkında teorik bilgi, deneyin amacı, deneyde kullanılan malzemeler, deneyin yapılışı, deneyin sonuçları ve hata payı hesaplamaları mutlaka mektupta yer almıştır.

- Öğretmen adaylarının mektup yazarken farklı kaynaklardan yararlanmaları gerektiği belirtilmiştir.

- Mektubu Türkçe yazım ve imla kurallarına uygun olarak hazırlamaları gerektiği belirtilmiştir.

- Resim, tablo, grafik, formül vb. ögelerin mektup içerisinde mektup formatına uygun olarak verilmesi istenmiştir.

- Mektupların en az 3 sayfa en fazla 6 sayfa halinde hazırlanmasi istenmiştir.

Öğretmen adaylarının mektup yazma çalışmalarını değerlendirmek amacıyla araştırmacılar tarafından Mektup Değerlendirme Rubriği hazırlanmıştır. Öğretmen adaylarının hazırladıkları mektuplar öncelikle değerlendirme rubriği baz alınarak araştırmacılar tarafından değerlendirilmiş ve sonrasında mektuplar Deney Grubu-3'e seçilen akranlarına araştırmacılar tarafından dağıtılarak onların değerlendirmesi sağlanmıştır.

Poster: Deney grubu-3 olarak seçilen grupta öğrenme amaçlı yazma türlerinden poster çalışılmıştır. Öğretmen adayları ikişer veya üçer kişilik gruplara ayrılmıştır. Öğretmen adayları laboratuvar çalışmalarını bu gruplarda araştırmacıların rehberliğinde gerçekleştirmiş fakat poster çalışmalarını bireysel yapmışlardır. Öğretmen adayları her hafta yaptıkları deneylerin raporlarını poster olarak hazırlayarak bir sonraki hafta yapılan derste araştırmacılara teslim etmiştir. Poster hazırlamada aşağıda belirtilen kriterler göz önünde bulundurulmuştur: 
- Posterlerin $70^{*} 100$ boyutlarında renkli fon kartonlarına hazırlanması istenmiştir.

- Hazırlanan posterlerin poster formatına uygun şekilde deney hakkında teorik bilgi, deneyin amacı, deneyde kullanılan malzemeler, deneyin yapılışı, deneyin sonuçları ve hata payı hesaplamaları mutlaka posterde yer almıştır.

- Öğretmen adaylarının poster hazırlarken farklı kaynaklardan yararlanmaları gerektiği belirtilmiştir.

- Posteri Türkçe yazım ve imla kurallarına uygun olarak hazırlamaları gerektiği belirtilmiştir.

- Resim, tablo, grafik, formül vb. ögelerin poster içerisinde poster formatına uygun olarak verilmesi istenmiştir.

- Öğretmen adaylarının her hafta için farklı orijinal poster tasarımları yapmaları istenmiştir.

- Posterler konuyu öğretecek şekilde öğretmen adaylarının akranlarına yönelik onların seviyesine uygun olarak hazırlanmıştır.

Öğretmen adaylarının hazırladıkları posterlerin değerlendirmeleri araştırmacılar tarafından hazırlanan Poster Değerlendirme Rubriği kullanılarak yapılmıştır. Posterler öncelikle araştırmacılar tarafından değerlendirilmiş ve daha sonra akran değerlendirmeleri için Deney Grubu-3'e seçilen öğretmen adaylarına dağıtılmıştır.

Poster ve Mektup Değerlendirme: Deney Grubu-3 olarak seçilen öğretmen adayları deney raporlarını klasik tarzda hazırlamışlar ve Deney Grubu-1 ve Deney Grubu-2'de yer alan akranlarının hazırladıkları posterleri ve mektupları değerlendirmişlerdir. Öğretmen adayları öncelikle ikişer veya üçer kişiden oluşan gruplara ayrılmışlardır. Ders kapsamında yapılması istenilen deneyleri her hafta bir deney olacak şekilde araştırmacıların rehberliğinde grup arkadaşları ile yapmışlardır. Her hafta yapılan deneyin raporu bir sonraki hafta derste araştırmacılara teslim edilmiştir. Bu gruptaki öğretmen adaylarının hazırladıkları klasik deney raporlarında aşağıda yer alan kriterlere dikkat edilmiştir:

- Öğretmen adayları derste gruplar halinde çalışmış, ancak deney raporlarını bireysel hazırlamışlardır. 
- Deney raporlarında deney hakkında teorik bilgi, deneyin amacl, deneyde kullanılacak malzemeler, deneyin yapılışı, deneyin sonuçları ve hata payı hesaplamaları yer almaktadır.

- Deney raporları hazırlanırken farklı kaynaklardan yararlanmaları gerektiği belirtilmiştir.

- Deney raporlarında Türkçe yazım ve imla kurallarına uymaları istenmiştir.

- Resim, tablo, grafik, formül gibi ögelerin kullanılması gerektiği vurgulanmıştır.

Öğretmen adaylarının hazırladıkları deney raporları her hafta araştırmacılar tarafından değerlendirilmiştir. Bu gruptaki öğretmen adaylarının poster ve mektupları değerlendirmelerinde aşağıdaki unsurlar göz önünde bulundurulmuştur:

- Öğretmen adaylarına öncelikle Poster Değerlendirme Rubriği ve Mektup Değerlendirme Rubriği hakkında bilgilendirme yapılmıştır.

- Değerlendirmelerin objektif olması hususunda gerekli uyarılar yapılmış ve değerlendirilen mektup ve posterlerin ayrıca araştırmacılar tarafından da değerlendirildiği vurgulanmıştır. Öğretmen adaylarının gelişigüzel, incelemeden değerlendirmelerinin önüne geçilmeye çalışılmış ve değerlendirmelerin titizlikle yapılması sağlanmaya çalışılmıştır.

- Haftalık olarak araştırmacılar tarafından seçilen mektup ve posterler öğretmen adaylarına dağıtılmıştır. Mektup ve posterler dağıtılırken hazırlayan öğretmen adaylarının isimleri kapatılmış ve öğretmen adayları değerlendirdikleri ödevlerin kim tarafından hazırlandığını bilmeden değerlendirmiştir. Bu sayede değerlendirmede objektifliğin artması sağlanmıştır.

- Öğretmen adayları değerlendirdikleri mektup ve posterler için rubrikler haricinde bir de kısa değerlendirme raporları yazmışlardır. $\mathrm{Bu}$ raporlarda mektup ve posterlerin eksik ve hatalı yönlerini, çok beğendikleri kısımları, en kusursuz noktalarını nedenleri ile yazmaları istenmiştir. Bu sayede öğretmen adaylarının akranlarının hazırladıkları mektup ve posterleri tam anlamıla eksiksiz olarak değerlendirmeleri sağlanmıştır.

- Öğretmen adaylarına değerlendirmeleri için çok iyi, iyi, orta, kötü ve çok kötü düzeyde hazırlanmış poster ve mektuplar karışık olarak 
dağıtılmış ve öğretmen adayları her iki türden de her düzeyden ödevleri değerlendirmiştir.

Klasik Deney Raporu: Kontrol grubuna seçilen öğretmen adayları öncelikle ikişer veya üçer kişiden oluşan gruplara ayrılmışlar ve laboratuvar çalışmalarını bu gruplarda gerçekleştirmişlerdir. Öğretmen adayları her hafta yaptıkları deneyin raporunu bir sonraki haftaya kadar hazırlayarak derste araştırmacılara teslim etmiştir. Öğretmen adaylarının hazırladıkları deney raporları araştırmacılar tarafından değerlendirilmiştir. Klasik deney raporu hazırlamada aşağıda yer alan unsurlara dikkat edilmiştir:

- Öğretmen adayları derste gruplar halinde çalışmış, ancak deney raporlarını bireysel hazırlamışlardır.

- Deney raporlarında deney hakkında teorik bilgi, deneyin amacl, deneyde kullanılacak malzemeler, deneyin yapılışı, deneyin sonuçları ve hata payı hesaplamaları yer almaktadır.

- Deney raporları hazırlanırken farklı kaynaklardan yararlanmaları gerektiği belirtilmiştir.

- Deney raporlarında Türkçe yazım ve imla kurallarına uymaları istenmiştir.

- Resim, tablo, grafik, formül gibi ögelerin kullanılması gerektiği vurgulanmıştır.

\section{Bulgular}

Öğretmen adaylarının öntest olarak uygulanan ABT-ön'den elde edilen verilerin betimsel istatistik sonuçları Tablo 1'de verilmiştir.

Tablo 1. ABT-ön'den elde edilen verilerin betimsel analiz sonuçları

\begin{tabular}{llll}
\hline Gruplar & N & X & SS \\
\hline Deney-1 & 24 & 27,54 & 9,34 \\
Deney-2 & 20 & 26,40 & 9,45 \\
Deney-3 & 24 & 30,79 & 10,26 \\
Kontrol & 20 & 30,25 & 10,79 \\
Toplam & 88 & 28,78 & 9,96 \\
\hline
\end{tabular}


Tablo 1'de görüldüğü gibi öğretmen adaylarının deneylerin teorik kısımlarına ait önbilgi düzeyleri arasında farklılıklar bulunmaktadır. Öğretmen adaylarının akademik başarılarında gözlenen bu farkların anlamlı olup olmadığını tespit etmek amacıyla tek yönlü ANOVA yapılmış ve analiz sonuçları Tablo 2'de verilmiştir.

Tablo 2. ABT-ön'den elde edilen verilerin ANOVA sonuçları

\begin{tabular}{llllll}
\hline Gruplar & $\begin{array}{l}\text { Karelerin } \\
\text { Toplamı }\end{array}$ & sd & $\begin{array}{l}\text { Karelerin } \\
\text { Ortalaması }\end{array}$ & F & p \\
\hline Gruplar arası & 290,431 & 3 & 96,810 &, 975 &, 409 \\
Gruplar içi & 8340,467 & 84 & 99,231 & & \\
Toplam & 8630,898 & 87 & & & \\
\hline
\end{tabular}

Tablo 2'de verilen analiz sonuçlarına göre mektup yazan, poster hazırlayan, mektup ve posterleri değerlendiren ve klasik tarzda deney raporu hazırlayan öğretmen adaylarının önbilgi düzeyleri arasında istatistiksel olarak anlamlı bir farklılık bulunmamaktadır; $\left(\mathrm{F}_{(3,84)}=, 975 ; \mathrm{p}>0,05\right)$.

Öğretmen adaylarının sontest olarak uygulanan ABT-son'den elde edilen verilerin betimsel istatistik sonuçları Tablo 3'te verilmiştir.

Tablo 3. ABT-son'dan elde edilen verilerin betimsel analiz sonuçlarn

\begin{tabular}{llll}
\hline Gruplar & N & X & SS \\
\hline Deney-1 & 24 & 71,08 & 7,29 \\
Deney-2 & 20 & 68,80 & 10,09 \\
Deney-3 & 24 & 65,67 & 6,69 \\
Kontrol & 20 & 55,30 & 3,67 \\
Toplam & 88 & 65,50 & 9,28 \\
\hline
\end{tabular}

Tablo 3'te görüldüğü gibi öğrenme amaçlı yazmada mektup yazan grubun akademik başarı ortalaması poster hazırlayan, mektup ve posterleri değerlendiren grupların ve kontrol grubunun akademik başarı ortalamasından yüksektir. Ayrıca poster ve değerlendirme grubunda yer alan öğretmen adaylarının akademik başarı ortalamaları kontrol grubundan yüksektir. Öğretmen adaylarının akademik başarılarında gözlenen bu farkların anlamlı olup olmadığını tespit etmek amacıyla tek yönlü ANOVA yapılmış ve analiz sonuçları Tablo 4'te verilmiştir. 
Tablo 4. ABT-son'dan elde edilen verilerin ANOVA sonuçları

\begin{tabular}{llclll}
\hline Gruplar & $\begin{array}{l}\text { Karelerin } \\
\text { Toplamı }\end{array}$ & SD & $\begin{array}{l}\text { Karelerin } \\
\text { Ortalaması }\end{array}$ & F & $\mathbf{p}^{*}$ \\
\hline Gruplar arası & 3047,433 & 3 & 1015,811 & 19,207 & 0,000 \\
Gruplar içi & 4442,567 & 84 & 52,888 & & \\
Toplam & 7490,000 & 87 & & & \\
\hline
\end{tabular}

${ }^{*} p<0,05$

Tablo 4'te verilen analiz sonuçlarına göre mektup yazan, poster hazırlayan, mektup ve posterleri değerlendiren ve klasik tarzda deney raporu hazırlayan öğretmen adaylarının akademik başarıları arasında istatistiksel olarak anlamlı bir farklılık bulunmaktadır; $\left(F_{(3,84)}=19,207\right.$; $\left.p<0,05 ; \quad \eta^{2}=0,407\right)$. Öğretmen adaylarının akademik başarılarında gözlenen bu değişkenliğin $\% 40,7$ oranında farklı şekillerde gerçekleştirilen öğrenme amaçlı yazmadan kaynaklandığı söylenebilir. Cohen (1988)'e göre bu değer çok büyük etki olarak sınıflandırılmaktadır. Öğretmen adaylarının akademik başarılarındaki anlamlı farkın hangi grupların lehine olduğunu tespit etmek amacıyla çoklu karşılaştırma testlerinden Bonferroni uygulanmıştır. Bonferroni testi sonuçlarına göre mektup ( $\left.X_{\text {Deney-1}}=71,08\right)$ ve klasik rapor $\left(X_{\text {Kontrol }}=55,30\right)$ yazan gruplar arasinda mektup yazan grup lehine, poster hazırlayan (Xeney-2 $=68,80)$ ve klasik rapor yazan gruplar arasında poster hazırlayan grup lehine ve mektup ve poster çalışmalarını değerlendiren ( $X_{\text {Deney- }}$ $\left.{ }_{3}=65,67\right)$ ve klasik deney raporu yazan gruplar arasında değerlendirme grubu lehine istatistiksel olarak anlamlı farklılık bulunmuştur.

Öğretmen adaylarının öntest olarak uygulanan LBT-ön'den elde edilen verilerin betimsel istatistik sonuçları Tablo 5'te verilmiştir.

Tablo 5. LBT-ön'dan elde edilen verilerin betimsel analiz sonuçları

\begin{tabular}{llll}
\hline Gruplar & N & X & SS \\
\hline Deney-1 & 24 & 18,58 & 7,24 \\
Deney-2 & 20 & 19,00 & 7,45 \\
Deney-3 & 24 & 19,54 & 7,08 \\
Kontrol & 20 & 18,15 & 7,82 \\
Toplam & 88 & 18,84 & 7,28 \\
\hline
\end{tabular}

Tablo 5'te görüldüğü üzere öğretmen adaylarının genel fizik laboratuvarı I dersine yönelik önbilgi düzeyleri arasında farklılıklar 
bulunmaktadır. Öğretmen adaylarının laboratuvara yönelik önbilgi düzeylerinde gözlenen bu farkların anlamlı olup olmadığını tespit etmek amacıyla tek yönlü ANOVA yapılmış ve analiz sonuçları Tablo 6'da verilmiştir.

Tablo 6. LBT-ön'den elde edilen verilerin ANOVA sonuçları

\begin{tabular}{llllll}
\hline Gruplar & $\begin{array}{l}\text { Karelerin } \\
\text { Toplamı }\end{array}$ & SD & $\begin{array}{l}\text { Karelerin } \\
\text { Ortalamas }\end{array}$ & F & p \\
\hline Gruplar arası & 23,431 & 3 & 7,810 &, 143 &, 934 \\
Gruplar içi & 4578,342 & 84 & 54,504 & & \\
Toplam & 4601,773 & 87 & & & \\
\hline
\end{tabular}

Tablo 6'da verilen analiz sonuçlarına göre mektup yazan, poster hazırlayan, mektup ve posterleri değerlendiren ve klasik tarzda deney raporu hazırlayan öğretmen adaylarının laboratuvara yönelik önbilgi düzeyleri arasında istatistiksel olarak anlamlı bir farklılık bulunmamaktadır; $(\mathrm{F}(3,84)=, 143 ; \mathrm{p}>0,05)$.

Öğretmen adaylarının sontest olarak uygulanan LBT-son'den elde edilen verilerin betimsel istatistik sonuçları Tablo $7^{\prime}$ de verilmiştir.

Tablo 7. LBT-son'dan elde edilen verilerin betimsel analiz sonuçlarn

\begin{tabular}{llll}
\hline Gruplar & N & X & SS \\
\hline Deney-1 & 24 & 71,67 & 8,41 \\
Deney-2 & 20 & 69,90 & 9,56 \\
Deney-3 & 24 & 73,62 & 8,67 \\
Kontrol & 20 & 63,30 & 9,42 \\
Toplam & 88 & 69,90 & 9,62 \\
\hline
\end{tabular}

Tablo 7'de görüldüğü üzere mektup ve posterleri değerlendiren grubun laboratuvar başarı ortalaması mektup yazan, poster hazırlayan ve kontrol gruplarının laboratuvar başarı ortalamasından yüksektir. Öğretmen adaylarının laboratuvar başarılarında gözlenen bu farkların anlamlı olup olmadığını tespit etmek amaciyla tek yönlü ANOVA yapılmış ve analiz sonuçları Tablo 8' de verilmiştir.

Tablo 8. LBT-son'dan elde edilen verilerin ANOVA sonuçları

\begin{tabular}{llllll}
\hline Gruplar & Karelerin Toplamı & SD & Karelerin Ort. & F & $\mathbf{p}^{*}$ \\
\hline Gruplar arası & 1279,121 & 3 & 426,374 & 5,285 & 0,002 \\
Gruplar içi & 6776,958 & 84 & 80,678 & & \\
Toplam & 8056,080 & 87 & & & \\
\hline
\end{tabular}


${ }^{*} \mathrm{p}<0,05$

Tablo 8'de verilen analiz sonuçlarına göre mektup yazan, poster hazırlayan, mektup ve posterleri değerlendiren ve klasik tarzda deney raporu hazırlayan öğretmen adaylarının laboratuvar başarıları arasında istatistiksel olarak anlamlı bir farklılık bulunmaktadır; $(F(3,84)=5,285$; $\left.p<0,05 ; \quad \eta^{2}=0,159\right)$. Öğretmen adaylarının laboratuvar başarılarında gözlenen bu değişkenliğin \%15,9 oranında uygulanan farklı aktivitelerden kaynaklandığı söylenebilir. Cohen (1988)'e göre bu değer büyük etki olarak sınıflandırılmaktadır. Öğretmen adaylarının laboratuvar başarılarındaki anlamlı farkın hangi grupların lehine olduğunu tespit etmek amacıyla çoklu karşılaştırma testlerinden Bonferroni uygulanmıştır. Bonferroni testi sonuçlarına göre mektup $\left(X_{\text {Deney-1 }}=71,67\right)$ ve klasik rapor $\left(X_{\text {Kontrol}}=63,30\right)$ yazan gruplar arasında mektup yazan grup lehine ve yine mektup ve poster çalışmalarını değerlendiren grup ( $X_{\text {Deney- }}$ $3=73,62$ ) ve klasik deney raporu hazırlayan gruplar arasında değerlendirme grubu lehine istatistiksel olarak anlamlı farklılık bulunmuştur.

Öğretmen adaylarının öğrenme amaçlı yazma kapsamında hazırladıkları mektup ve poster ödevlerinden aldıkları puanlar arasında istatistiksel olarak anlamlı fark olup olmadığını tespit etmek amacıyla yapılan bağımsız gruplar t-testi sonuçları Tablo 9' da verilmiştir.

Tablo 9. Mektup ve poster puanlarının bağımsız gruplar t-testi sonuçlar

\begin{tabular}{lllllll}
\hline Grup & $\mathbf{N}$ & $\mathbf{X}$ & ss & df & t & p \\
\hline Mektup & 24 & 72,83 & 6,60 & 42 &, 564 &, 576 \\
Poster & 20 & 71,60 & 7,91 & & & \\
\hline
\end{tabular}

Tablo 9'da verilen analiz sonuçlarına göre öğrenme amaçlı yazma kapsamında mektup ve poster çalışan öğretmen adaylarının hazırladıkları mektup ve posterlerden aldıkları puanların ortalaması arasında istatistiksel olarak anlamlı bir farklılığın olmadığı tespit edilmiştir; $\left(t_{(42)}=, 564 ; p>0,05\right)$.

\section{Tartışma ve Sonuç}

$\mathrm{Bu}$ araştırmanın temel amacı; mektup yazma, poster hazırlama aktivitelerinin ve bunları değerlendirmenin etkilerini çeşitli boyutlarda 
incelemektir. Elde edilen bulgular doğrultusunda aşağıdaki sonuçlara ulaşılmıştır.

Yapılan 10 deneyin raporunu mektup formatında hazırlayan öğretmen adayları (DG1) ile klasik deney raporu hazırlayan öğretmen adaylarının (KG) akademik başarıları arasında mektup hazırlayan lehine, poster formatında hazırlayan öğretmen adayları (DG2) ile klasik deney raporu hazırlayan öğretmen adaylarının (KG) akademik başarıları arasında poster hazırlayan lehine, klasik deney raporu yazıp mektup ve posterleri değerlendiren öğretmen adayları (DG3) ile klasik deney raporu hazırlayan öğretmen adaylarının (KG) akademik başarıları arasında değerlendirme grubu öğretmen adayları lehine anlamlı bir farklılık olduğu bulunmuştur. Öğrenme amaçlı yazma aktivitelerinden mektup yazma ve poster hazırlama ve bunları değerlendirme etkinlikleri, yapılan araştırmaların sonuçları ile araştırmanın ortaya koyduğu sonuçlar paralellik göstermekte ve birbirini desteklemektedir. Akçay ve Hand (2008), fen derslerinde mektup yazma gibi farklı ÖAY aktiviteleri yaptırmanın onların fen dersine karşı motivasyonu artırdığını ileri sürmüşlerdir. Yıldız ve Büyükkasap (2011), kuantum fiziği konularını öğrenirken mektup yazmanın akademik başarıya etkisinin istatiksel olarak anlamlı olduğu sonucuna ulaşmışlardır. Yeşildağ (2009) ise poster hazırlamanın öğrencilerin fen konularını daha kolay öğrenmelerini, bildikleri ya da bilmedikleri konuların farkına varmalarını sağladığını ifade etmiştir. Ayrıca alanyazında öğrenme amaçlı yazma etkinliklerini değerlendirmenin de öğrenmeye katkı sağladığı ileri sürülmüş (Sebba vd., 2008; Yeşildağ, 2009) ve üç deney grubunun da kontrol grubuna göre akademik başarıyı artırmada alanyazında tutarlı sonuçlar elde edilmiştir. $\mathrm{Bu}$ bağlamda öğrenme amaçlı yazma ve bunları değerlendirmenin öğrencilerin öğrenmelerini olumlu yönde etkilediği alanyazında birçok çalışma yer almaktadır (Akçay, Özyurt ve Akçay, 2014; Bozat ve Yıldız, 2014; Daşdemir, Cengiz ve Uzoğlu, 2015; Günel, Atilla ve Büyükkasap, 2009; Günel, Uzoğlu ve Büyükkasap, 2009; Hand, Yang ve Bruxvoort, 2007; Koçak, 2013; Uzoğlu ve Gürbüz, 2013; Yeşildağ Hasançebi ve Günel, 2013; Y1ldız, 2014, Yıldız ve Büyükkasap, 2011).

Araştırmada elde edilen bir başka bulguda, raporunu mektup formatında hazırlayan öğretmen adayları (DG1) ve mektup ve posterleri değerlendiren öğretmen adayları (DG3) ile kontrol grubu arasında la- 
boratuvar başarıları arasında DG1 ve DG3 lehine anlamlı fark çıkmıştır. Mektup yazan ve değerlendirme yapan öğretmen adaylarının kontrol grubuna göre laboratuvar başarısının yüksek olması, mektup yazarken ve değerlendirme yaparken; daha çok duygularını katarak, daha özümseyerek yazmaları ile ilişkilendirilebilir. Mektup yazmanın; konuyu günlük hayatta kullanma, konuyu pekiştirme, araştırma yapma, konuyu etkili, ayrıntılı ve kalıcı öğrenme, fizik dersine olumlu bakış açısını geliştirme, muhakeme gücünü artırma, konuşma ve yazma yeteneğini geliştirme gibi durumlarda etkili olduğu ifade edilebilir (Koçak ve Seven, 2016). Ayrıca akran değerlendirmenin becerilerin gelişimini sağladığı düşünüldüğünde (Temizkan, 2009), laboratuvar becerisine de katkı sağladığı düşünülebilir. Poster hazırlamada herhangi bir farkın çıkmaması, poster hazırlamanın daha çok görsel boyuta odaklanması ile ilişkilendirilebilir. Nitekim Yeşildağ Hasançebi ve Günel (2013) bir çalışmalarında öğrencilere ÖAY aktivitelerinde (poster) hangi modları kullanmayı tercih ettikleri sorulduğunda ise öğrencilerin \% 68.4'ü birinci olarak resim tercih ederken \%51.3'ü ikinci mod olarak metni kullanmay tercih ettiğini belirtmişlerdir. Bu durum laboratuvar başarısında, poster hazırlamanın; mektup yazmaya göre içselleştirme yapmadan, hazır ürüne ulaşmanın dezavantajı olarak açıklanabilir.

Araştırmada elde edilen bir diğer bulgu ise; öğrenme amaçlı yazma kapsamında mektup ve poster hazırlayan öğretmen adaylarının hazırladıkları mektup ve posterlerden aldıkları puanların ortalaması arasında bir farklılık bulunmamasıdır. Bu durum hem mektup, hem poster hazırlamanın öğrenme amaçlı yazma aktivelerinden olması (Prain and Hand, 1999) ve her iki öğrenme amaçlı yazma türünün de öğretmen adayları tarafından çok özverili ve çaba sarf ederek hazırlanmış olmasından olabilir. Çünkü ÖAY bilgileri sentezleyen ve kavramsal çerçeveyi ana hatları ile yapılandıran süreçtir (Bangert-Drowns, Hurley and Wilkinson, 2004).

$\mathrm{Bu}$ araştırma ve yapılan diğer araştırmalar da göz önüne alınırsa öğreticilerin derslerinde öğrenme amaçlı yazma aktivitelerini kullanmaları birçok açıdan faydalı olacaktır. ÖAY aktiviteleri öğrencilerin öğrenmelerine katkıda bulunarak, onların yorumlama, hatırlama, iletişim kurma ve pekiştirme, kavram değişimi sağlama gibi becerilerinin 
gelişimine yardımcı olur (Günel, Uzoğlu ve Büyükkasap, 2009; Mason and Boscolo, 2000; Tynjala,1998).

\section{Öneriler}

Öğrenme amaçlı yazma etkinlikleri öğrencilerin farklı durumlardaki gelişimleri için katkı sağlamaktadır. Bu tür çalışmaların uygulanması öğrenci verimliliğini artırıp, onların perspektiflerini genişletecektir. Araştırma sonucunda mektup yazma ve poster hazırlamanın etkileri incelenmiştir. Alanyazında mektup yazma, şiir yazma, günlük tutma, broşür hazırlama gibi öğrenme amaçlı yazma etkinlikleri çalışılmıştır (Bozat, 2014; Hasançebi vd., 2017). Farklı öğrenme amaçlı yazma etkinlikleri (kavram ağı, senaryo, köşe yazısı, slayt gösterisi...), farklı muhataplara yönelik (öğretmen, kardeş, ebeveyn...), farklı konularda hazırlattırılabilir ve bu yazma etkinliklerinin başarı üzerindeki etkisi incelenebilir. $\mathrm{Bu}$ doğrultuda, öğrencilere fen bilimlerinde daha fazla yazma pratiği yapma olanağı sağlamanın önemli olduğu görülmektedir (Farrell, 2001). Bu araştırmada olduğu gibi daha içten samimi bir dilin kullanıldığı mektup ile daha hazır kalıp bilgilerin kullanıldığı poster etkinliklerinin bu araştırmadan farklı olarak tutum, ilgi veya davranışlara yönelik etkisinin incelendiği araştırmalar yapılabilir. Nitel boyutta gözlem ve görüşmeler yapılarak ayrıntılı olarak ele alınabilir. Ayrıca öğrenme amaçlı yazmada çıan ürünlerin materyal analizleri yapilabilir. 
EXTENDED ABSTRACT

\section{Investigation of the Effect of Writing to Learn Activi- ties on Academic and Laboratory Achievement of Preservice Science Teachers \\ Emre Yıldız - Gülşen Koçak Atatürk University}

The letter is generally used to make statements to a correspondent on the subject determined as a writing to learn activity (Aktepe, 2020; Uzoğlu ve Gürbüz, 2013). Since the letter is written for an interlocutor, the writer's effort to be explanatory is at the forefront. The purpose of writing a letter; is to be able to explain the subject, event, or concept he wrote about in the easiest way to be understood (Y1ldiz, 2014). A poster is a type of writing for learning, in which students can summarize their work with pictures and graphics. Graphics, tables, pictures, examples, and other works of art are used to make the poster visually interesting and to attract attention to key points (Köklü, 2001). Each type of writing to learn activities such as writing letters and preparing posters has serious contributions to the literature. Considering the international studies, although there is wide coverage of writing to learn activity (Daşdemir, Cengiz and Uzoğlu, 2015), it has not reached the desired point in the national literature yet. In this study, it is expected that examining different types of writing for learning purposes together as an alternative instead of writing traditional reports in the laboratory environment will contribute to the researches to be done in the related field.

This research aimed to determine the effects of different writing to learn activities on academic and laboratory achievement of pre-service science teachers, and compare writing to learn scores. In this context, the following research questions tried to be answered:

- Is there a statistically significant difference between the academic achievements of the pre-service teachers who wrote letters, prepared posters, evaluated these learning activities prepared by their peers and prepared classical reports? 
- Is there a statistically significant difference between the laboratory achievement of the pre-service teachers who wrote letters, prepared posters, evaluated these learning writing activities prepared by their peers, and prepared classical reports?

- Is there a statistically significant difference between pre-service teachers' letter writing and poster preparation scores?

In the research, quantitative research model was adopted and quasiexperimental design with pretest-posttest comparison groups among experimental designs was used. This research was conducted with 88 first-year science teacher candidates. Academic achievement test, laboratory achievement test, letter and poster evaluation rubrics were used as data collection tools. Descriptive statistics, one-way ANOVA, and independent samples t-test were used in the analysis of the data obtained from the application.

The application was carried out by the researchers in the General Physics Laboratory I course for 13 weeks (2 consecutive weekly lessons) in all control and experimental groups. In the experimental group-1, the laboratory reports were prepared with a letter, and in the Experiment Group-2 with a poster. Experimental Group-3 prepared the laboratory reports with the classical report method and in addition to this, the letters and posters prepared by the teacher candidates in the Experimental Group-1 and 2 were evaluated. The pre-service teachers in the group selected as the control group prepared their laboratory reports with the classical report method.

It was determined that there is no statistically significant difference between the pre-knowledge levels of the pre-service teachers and their prior knowledge about the laboratory. At the end of the application, a significant difference was found between the groups who wrote letters and classical reports in terms of academic achievement of the pre-service teachers in favor of the group who wrote the letter, the groups that prepared posters and wrote classical reports in favor of the group that prepared posters, and between the groups that evaluated the letter and poster works and wrote the classic experiment report, in favor of the evaluation group.

At the end of the application, a significant difference was found between the groups who wrote letters and classical reports in terms of la- 
boratory achievement of the pre-service teachers in favor of the group who wrote the letter, the groups that prepared posters and wrote classical reports in favor of the group that prepared posters, and between the groups that evaluated the letter and poster works and wrote the classic experiment report, in favor of the evaluation group.

It was determined that there is no statistically significant difference between the average of the scores obtained from the letters and posters prepared by the teacher candidates who worked on letters and posters within the scope of writing for learning purposes. Considering this research and other researches, it will be beneficial for teachers to use learning writing activities in their lessons. TAC activities contribute to students' learning, helping them to develop their skills such as interpreting, remembering, communicating and reinforcing, and providing concept change.

\section{Kaynakça / References}

Akyol, H. (2001). Türkçe ilkokuma yazma öğretimi. Ankara: Gündüz Eğitim ve Yayıncilik.

Akçay, H., ve B. Hand. (2008). "Farklı şekillerde uygulanan yaparak ve yazarak öğrenme metotlarının ilköğretim öğrencilerinin fen öğrenimine katkısı." VIII. Ulusal Fen Bilimleri ve Matematik Ĕ̆itimi Kongresi, Abant İzzet Baysal Üniversitesi Ĕ̆itim Fakültesi, Bolu.

Akçay, H., Özyurt, B. B., ve Akçay, B. B. (2014). Çoklu yazma etkinliklerinin fen ve teknoloji dersi öğretiminde kullanılmasının öğrenci başarısı ve kavram öğrenmeye etkisi. Bayburt Ĕ̆itim Fakültesi Dergisi, 9(2), 15-31.

Aktepe, Z. T. (2017). Dördüncü sınıf maddeyi tanıyalım ünitesinde öğrenme amaçlı yazma etkinliklerinin akademik başarıya etkisinin araştırılması (Yayımlanmamış Doktora Tezi). Atatürk Üniversitesi, Erzurum.

Bangert-Drowns, R. L., Hurley, M. M., and Wilkinson, B. (2004). The effects of school-based writing-to-learn interventions on academic achievement: A meta-analysis. Review of educational research, 74(1), 29-58.

Brewster, C., and Klump, J. (2004). Writing to learn, learning to write: Revisiting writing across the curriculum in northwest secondary schools. Portland, Oregon: Northwest Regional Educational Laboratory. 
Bozat, Ö. (2014). 5. sını yaşamımızdaki elektrik ünitesinde öğrenme amaçl yazma etkinliklerinden mektubun başarıya etkisi (Yayımlanmamış Yüksek Lisans Tezi). Atatürk Üniversitesi, Erzurum.

Bozat, Ö., ve Yıldız, A. (2014). 5. sınıf yaşamımızdaki elektrik ünitesinde öğrenme amaçlı yazma etkinliklerinden mektubun başarıya etkisi. Education Sciences, 10(4), 291-304.

Carter, M. (2007). Ways of knowing, doing, and writing in the disciplines. College Composition and Communication, 385-418.

Chatel, R.G. (1997). Writing to learn in science. A Curriculum Guide.

Chi, M. T. H. (2009). Active-constructive-interactive: A conceptual framework for differentiating learning activities. Topics in Cognitive Science, 1, 73-105.

Comer, D., Clark, C., and Canelas, D. (2014). Writing to learn and learning to write across the disciplines: Peer-to-peer writing in introductorylevel MOOCs. IRRODL, 15(5), 26-82.

Daşdemir, İ., Cengiz, E., and Uzoğlu, M. (2015). Öğrenme amaçlı yazma aktivitelerinden mektup yazmanın 7. sınıf ışık ünitesinde öğrencilerin akademik başarılarına ve bilimsel tutumlarına etkisi. Sosyal Bilimler Arastirmalari Dergisi, 5(11), 89-103

Dunlosky J, Rawson KA, Marsh EJ, Nathan MJ, Willingham DT (2013). Improving students' learning with effective learning techniques promising directions from cognitive and educational psychology. Psychological Science in the Public Interest, 14, 4-58.

Emig, J. (1977). Writing as a mode of learning. College Composition and Communication, 28, 122-128.

Farrell, M. P. (2001). Physics, writing and attainment. Physics Education, $36(1), 40-43$.

Gregg, L. W., and Steinberg, E. R. (Eds.). (2016). Cognitive processes in writing. Routledge.

Gunel, M., Hand, B., and McDermott, M. A. (2009). Writing for different audiences: Effects on high-school students' conceptual understanding of biology. Learning and instruction, 19(4), 354-367.

Gunel, M., Hand, B., and Prain, V. (2007). Writing for learning in science: A secondary analysis of six studies. International Journal of Science and Mathematics Education, 5(4), 615-637. 
Günel, M., Atila, M. E., ve Büyükkasap, E. (2009). Farklı betimleme modlarının öğrenme amaçlı yazma aktivitelerinde kullanımlarının 6 . sınıf yaşamımızdaki elektrik konusunun öğrenimine etkisi. Ilköğretim Online, 8(1), 183-199.

Günel, M., Uzoğlu, M., ve Büyükkasap, E. (2009). Öğrenme amaçlı yazma aktivitelerinin kullanımının ilköğretim seviyesinde kuvvet konusunu öğrenmeye etkisi. Gazi Ĕ̆itim Fakültesi Dergisi, 29(1), 379-399.

Haley-James, S. (1982). Helping students learn through writing. Language Arts, 59(7), 726-731.

Hand, B., and Prain, V. (2002). Teachers implementing writing-to-learn strategies in junior secondary science: A case study. Science Education, 86, 737-755.

Hand, B., Shelley, M. C., Laugerman, M., Fostvedt, L., and Therrien, W. (2018). Improving critical thinking growth for disadvantaged groups within elementary school science: A randomized controlled trial using the Science Writing Heuristic approach. Science Education, 102(4), 693-710.

Hand, B., Yang, O.E.M. and Bruxvoort, C. (2007). Using writing-to-learn science strategies to improve year 11 students' understanding of stoichiometry. International Journal of Science and Mathematics education, 5, 125-143.

Hasançebi, F. Y., Koçak, G., Köksal, A. P., ve Seven, S. (2017). Öğrenme amaçlı yazmanın modern fizik konularını öğrenmede ve öğrenciler üzerinde etkisi. Bayburt Eğitim Fakültesi Dergisi, 12(24), 649-666.

Jang, J. Y., and Hand, B. (2017). Examining the value of a scaffolded critique framework to promote argumentative and explanatory writings within an argument-based inquiry approach. Research in science education, 47(6), 1213-1231.

Klein, P. (1999). Reopening inquiry into cognitive processes in writing-tolearn. Educational Psyc82013hology Review, 11, 203-270.

Koçak, G. (2013). Tek boyutta hareket konusunda öğrenme amaçl yazma etkinliklerinin uygulanmasının fen bilgisi öğretmenliği 1. sınıf öğrencilerinin akademik başarısına ve kalıcılı̆̆a etkisi (Yayımlanmamış Yüksek Lisans Tezi). Atatürk Üniversitesi, Erzurum.

Koçak, G., ve Seven, S. (2016). Fen bilgisi öğretmen adaylarının öğrenme amaçlı yazma etkinlikleri hakkındaki görüşleri: Tek boyutta hareket örneği. EKEV Akademi Dergisi, 65, 253-268. 
Köklü, N. (2001). Eğitim araştırmaları derslerinde poster oturumları. Ĕğitim ve Bilim, 26(119), 32-38.

Lamb, R., Hand, B., and Yoon, S. (2017). Examinations of cognitive processing of science writing tasks. Journal of Psychology and Brain Studies, 1(1), 1-5.

Mason, L., and Boscolo, P. (2000). Writing and conceptual change. What changes?. Instructional Science, 28(3), 199-226.

McDermott, M. A., and Hand, B. (2010). A secondary reanalysis of student perceptions of non-traditional writing tasks over a ten year period. Journal of Research in Science Teaching: The Official Journal of the National Association for Research in Science Teaching, 47(5), 518-539.

McMillan, J. H., and Schumacher, S. (2010). Research in education. Evidencebased research. (7th ed.). Boston: Pearson Education, Inc.

Norris, S. P., and Phillips, L. M. (2003). How literacy in its fundamental sense is central to scientific literacy. Science education, 87(2), 224-240.

Prain, V. (2006). Learning from writing in secondary science: Some theoretical and practical implications. International Journal of Science Education, 28(2-3), 179-201.

Prain, V., and Hand, B. (1999). Students perceptions of writing for learning in secondary school science. Science Education, 83(2), 151-162.

Prain, V., and Hand, B. (2016). Coming to know more through and from writing. Educational Researcher, 45(7), 430-434.

Sinaga, P., and Feranie, S. (2017). Enhancing critical thinking skills and writing skills through the variation in non-traditional writing task. International Journal of Instruction, 10(2), 69-84.

Sorcinelli, M. D., and Elbow, P. (1997). Writing to learn: Strategies for assigning and responding to writing across the disciplines. Jossey-Bass.

Temizkan, M. (2009). Akran değerlendirmenin konuşma becerisinin geliştirilmesi üzerindeki etkisi. Mustafa Kemal Üniversitesi Sosyal Bilimler Enstitüsü Dergisi, 6(12), 90- 112.

Tynjälä, P. (1998). Writing as a tool for constructive learning: Students' learning experiences during an experiment. Higher Education, 36(2), 209230.

Uzoğlu, M., ve Gürbüz, F. (2013). Fen ve teknoloji öğretmen adaylarının isı ve sicaklık konusundaki kavram yanılgilarının belirlenmesinde öğrenme amaçlı mektup yazma aktivitesinin kullanılmas1. International Journal of Social Science, 4(6), 501-517. 
Uzun, F. (2013). Bağlam temelli yaklaşıma dayalı genel fizik-ı laboratuvar dersinin fen bilgisi öğretmen adaylarının başarılarına, bilimsel süreç becerilerine, motivasyonlarına ve hatırlamalarına etkisi (Yayımlanmamış Yüksek Lisans Tezi). Marmara Üniversitesi, İstanbul.

Yaman, F. (2018). Öğrenme amaçlı yazma etkinliklerinin ortaokul 6. sınıf öğrencilerinin madde ve isı ünitesindeki kavramsal anlamalarına etkisi. Sakarya University Journal of Education, 8(4), 89-108.

Yeşildă̆, F. (2009). Modern fizik öğretiminde öğrencilerin çoklu modsal betimlemeleri algilamalar ve modsal betimlemelerle hazırladikları yazma aktivitelerini değerlendirme sürecinin öğrenmeye etkisi. (Yayımlanmamış Yüksek Lisans Tezi). Atatürk Üniversitesi, Erzurum.

Yesildag-Hasançebi, F., ve Günel, M. (2013). College students' perceptions toward the multi modal representations and instruction of representations in learning modern physics. Eurasian Journal of Educational Research, 53, 197-214.

Yıldız, A. (2014). Öğrenme amaçlı yazma aktivitesi olarak mektup ve etkili kullanımı. Turkish Studies, 9(5), 2097-2104.

Yıldız, A., ve Büyükkasap, E. (2011). Öğretmen adaylarının fotoelektrik olayını anlama düzeyleri ve öğrenme amaçlı yazmanın başarıya etkisi. Kuram ve Uygulamada Ĕ̆itim Bilimleri, 11(4), 2259-2274.

Yore, L. D., Hand, B., and Prain, V. (1999). Writing-to-learn science: Breakthroughs, barriers, and promises. Paper presented at the International Conference of the Association for Educating Teachers in Science, Austin, TX. (ERIC Document Reproduction Service No. ED441688)

\section{Kaynakça Bilgisi / Citation Information}

Yıldız, E. ve Koçak, G. (2021). Öğrenme amaçlı yazma etkinliklerinin fen bilgisi öğretmen adaylarının akademik ve laboratuvar başarılarına etkisinin incelenmesi. OPUS-Uluslararası Toplum Araştırmaları Dergisi, 18(39), 431-458. DOI: 10.26466/opus.846031. 